\title{
Effects of Reheating Duration on the Microstructures and Tensile Properties of Thixoforged In Situ $\mathrm{Mg}_{2} \mathrm{Si}_{\mathrm{p}} / \mathrm{AM60B}$ Composites
}

\author{
Tijun Chen $\cdot$ Suqing Zhang $\cdot$ Yushi Chen $\cdot$ Yuandong Li $\cdot$ Ying Ma $\cdot$ Yuan Hao
}

Received: 15 May 2014/Revised: 29 August 2014/Published online: 7 October 2014

(C) The Chinese Society for Metals and Springer-Verlag Berlin Heidelberg 2014

\begin{abstract}
The influences of reheating duration on microstructures and tensile properties of thixoforged in situ $\mathrm{Mg}_{2} \mathrm{Si}_{\mathrm{p}} /$ AM60B composites have been investigated. The results indicate that the reheating time affects the volume fraction, composition and distribution of the liquid phase, the evolution of the liquid pools within the primary particles, and the morphology and distribution of the $\mathrm{Mg}_{2} \mathrm{Si}$ particles of the semisolid feedstock. These changes then affect the subsequent solidification behavior and deformation mechanism during thixoforging, which are responsible for the resulting microstructure and tensile properties. $\mathrm{Mg}_{2} \mathrm{Si}$ particles play a strengthening role for the matrix through the load transfer mechanism. The appropriate reheating time is $60 \mathrm{~min}$ at $600{ }^{\circ} \mathrm{C}$ when the mold preheating temperature is at $300{ }^{\circ} \mathrm{C}$. The ultimate tensile strength and elongation of the resulting composite are up to $209 \mathrm{MPa}$ and $11.9 \%$, respectively.
\end{abstract}

KEY WORDS: In situ synthesis; Magnesium matrix composites; Semisolid; Mechanical properties

\section{Introduction}

In the last two decades, magnesium alloys have received more attention as important materials in electronic products, portable tools, sporting goods, and aerospace vehicles because of their low density, high specific strength and stiffness, good electromagnetic shielding characteristics, and good machinability [1-3]. AM60B is a most widely used aluminum-bear magnesium alloy and has a good combination of cast-ability and low cost [4]. However, its applications are very limited due to the poor mechanical properties under high temperature compared with those of another

Available online at http://link.springer.com/journal/40195

T. Chen $(\bowtie) \cdot$ S. Zhang $(\bowtie) \cdot$ Y. Chen $\cdot$ Y. Li $\cdot$ Y. Ma .

Y. Hao

Key laboratory of Advanced Processing and Recycling of

Nonferrous Metals, Lanzhou University of Technology, Lanzhou

730050, China

e-mail: chentj1971@126.com

S. Zhang

e-mail: zhangsuqing1985@163.com family of lightweight alloys, aluminum alloys, and it suffers from the challenge in meeting the requirements of many fields. Metal-matrix composites not only have good hightemperature mechanical properties, but also have good wear resistance and dimensional stability. So, they have been used in aircraft, space, defense, and automotive industries [5]. Thus, the most maneuverable and reliable way to overcome the shortcomings of AM60B alloy is to incorporate or to generate thermally stable particles to form composites [6].

It is well known that $\mathrm{Mg}_{2} \mathrm{Si}$ phase is one kind of stable intermetallic that exists in $\mathrm{Mg}-\mathrm{Si}$ binary system. $\mathrm{Mg}_{2} \mathrm{Si}$ particle has high melting point, high hardness, low density, high elastic modulus, and low coefficient of thermal expansion, and thus is an ideal reinforcement for magnesium alloys [7, 8]. Thus, adding silicon element into AM60B alloy melt to form in situ $\mathrm{Mg}_{2} \mathrm{Si}$ particles reinforced composites $\left(\mathrm{Mg}_{2} \mathrm{Si}_{\mathrm{p}} / \mathrm{AM} 60 \mathrm{~B}\right)$ should be considered as one of the most potential way to improve mechanical properties of this alloy [7, 9]. However, the coarse dendritic primary $\mathrm{Mg}_{2} \mathrm{Si}$ and the brittle Chinese script eutectic $\mathrm{Mg}_{2} \mathrm{Si}$ result in relatively poor properties. Therefore, it cannot be accepted by the engineering community for 
conventional applications. In the authors' previous investigations, modification of $\mathrm{Mg}_{2} \mathrm{Si}$ particles has been achieved via traditional gravity casting by addition of $\mathrm{Mg}$ $30 \mathrm{Sr}$ master alloy [10]. Modified $\mathrm{Mg}_{2} \mathrm{Si}$ particles with grain size of $20-40 \mu \mathrm{m}$ were uniformly distributed in the matrix.

As a novel metal processing technology, thixoforming combines the advantages of both casting and forging technologies and offers many advantages [11]. More importantly, it can significantly decrease or even eliminate porosities, and thus can significantly improve mechanical properties $[12,13]$. For the alloy being suitable for thixoforming, it must have an appreciable solidification range and a semisolid microstructure consisted of small and spheroidal primary particles uniformly suspended in liquid phase after being partial remelting $[14,15]$. AM60B as a well-known hypoeutectic alloy, has a quite wide solidification range and an ideal semisolid microstructure for thixoforming after being partial remelting if it is properly grain refined [16, 17]. In a previous research [18], the in situ $\mathrm{Mg}_{2} \mathrm{Si}_{\mathrm{p}} / \mathrm{AM} 60 \mathrm{~B}$ composite refined and modified by $\mathrm{SiC}$ particles and $\mathrm{Sr}$, respectively, could obtain such a nondendritic semisolid microstructure after partial remelting.

Unfortunately, most of the existing investigations have emphasized on the microstructural evolution during partial remelting of matrix alloys [16-21]. Only a few literatures have involved the microstructures and mechanical properties of the "thixoforged" alloys [22-24]. The investigations that are related to the composites are far laggard behind the monolithic alloys. It is well known that the mechanical properties were determined by the microstructures, and the microstructures were controlled by the processing parameters. So, it is very important to clarify the effects of the processing parameters on microstructure and mechanical properties of the thixoformed composites. In this work, the effect of reheating duration on the microstructures and mechanical properties of thixoforged in situ $\mathrm{Mg}_{2} \mathrm{Si}_{\mathrm{p}} /$ AM60B modified by $\mathrm{SiC}$ and $\mathrm{Sr}$ has been studied.

\section{Experimental}

The in situ $\mathrm{Mg}_{2} \mathrm{Si}_{\mathrm{p}} / \mathrm{AM} 60 \mathrm{~B}$ composites used in this work were prepared by liquid metallurgy route using commercial AM60B magnesium alloy, purity $\mathrm{Mg}$, and commercial Al$30 \mathrm{Si}$. The used modifier and grain refiner are $\mathrm{Mg}-30 \mathrm{Sr}$ and $\mathrm{SiC}_{\mathrm{p}}$, respectively. A quantity of AM60B alloy, pure $\mathrm{Mg}$, and $\mathrm{Al}-30 \mathrm{Si}$ master alloy was melted in an electric resistance furnace at $790{ }^{\circ} \mathrm{C}$, and then modified by $0.5 \mathrm{wt} \% \mathrm{Sr}$ (using $\mathrm{Mg}-30 \mathrm{Sr}$ master alloy). The melt was then isothermally held for $20 \mathrm{~min}$, and $0.2 \mathrm{wt} \% \mathrm{SiC}_{\mathrm{p}}$ (using pressed cake of $\mathrm{Mg}-25 \mathrm{SiC}_{\mathrm{p}}$ mixture powders) was introduced. Finally, the resulting melt was degassed using $\mathrm{C}_{2} \mathrm{Cl}_{6}$ and

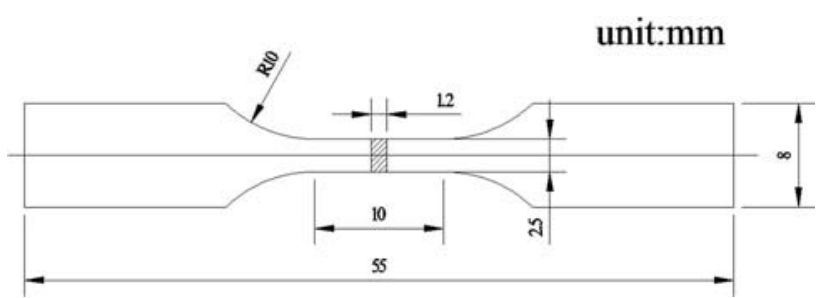

Fig. 1 Schematic of the tensile testing specimen

pour into a steel mold with a cavity of $\$ 50 \mathrm{~mm} \times 500 \mathrm{~mm}$ after it has been held for $10 \mathrm{~min}$. The resultant ingots with $2 \mathrm{wt} \% \mathrm{Si}$ were obtained. A covering agent of RJ-2 designed for magnesium alloys was used for protecting the melt from oxidation during melting.

For the thixoforging, some ingots with dimensions of $\Phi 42 \mathrm{~mm} \times 30 \mathrm{~mm}$ were cut from the as-cast rods, and then heated in a resistant furnace under argon gas protection at a semisolid temperature of $600{ }^{\circ} \mathrm{C}$ for different durations (ranging from 50 to $120 \mathrm{~min}$ ). A hole with a diameter of $1.5 \mathrm{~mm}$ and a depth of $5 \mathrm{~mm}$ was drilled along the center axis of an ingot and a thermocouple was mounted in it in order to examine the temperature change during partial remelting. The obtained semisolid feedstocks were quickly handled into a die with a cavity of $\Phi 50 \mathrm{~mm} \times 20 \mathrm{~mm}$ and then thixoforged. The preheating temperature of the die was $300{ }^{\circ} \mathrm{C}$ and graphite powders were used as lubricant during forming. Thixoforging process was performed using a hydraulic press machine. The applied punch velocity and pressure were $60 \mathrm{~mm} / \mathrm{s}$ and $192 \mathrm{MPa}$, respectively, and the holding time was $20 \mathrm{~s}$.

The specimens for tensile testing were machined by $\mathrm{CNC}$ wire-cut machine from the center of each thixoforged products parallel to the forging pressure (Fig. 1). Tensile testing was conducted on a universal material testing machine with a loading velocity of $1 \mathrm{~mm} / \mathrm{s}$. The average of at least five testing values was taken as that of a specimen. The metallographic specimens were cut from the center and edge regions of each product, and one cross-section parallel to the forging direction was finished and polished by standard metallographic techniques. Subsequently, the specimens were chemically etched using $4 \%$ nitric acid ethanol solution and observed on a scanning electron microscope (SEM) and an optical microscope (OM). The compositions of primary particles in the microstructures were examined by energy dispersive spectroscopy (EDS) in the SEM. To examine the eutectic $\beta$ phase amount, the related SEM images were analyzed by Image-Pro Plus 5.0 software, and the area ratio of the $\beta$ phase to the whole was taken as its amount. The specimens from the center of the composites were solution treated for $1 \mathrm{~h}$ at $430{ }^{\circ} \mathrm{C}$ and observed again on the optical microscope to analyze the 

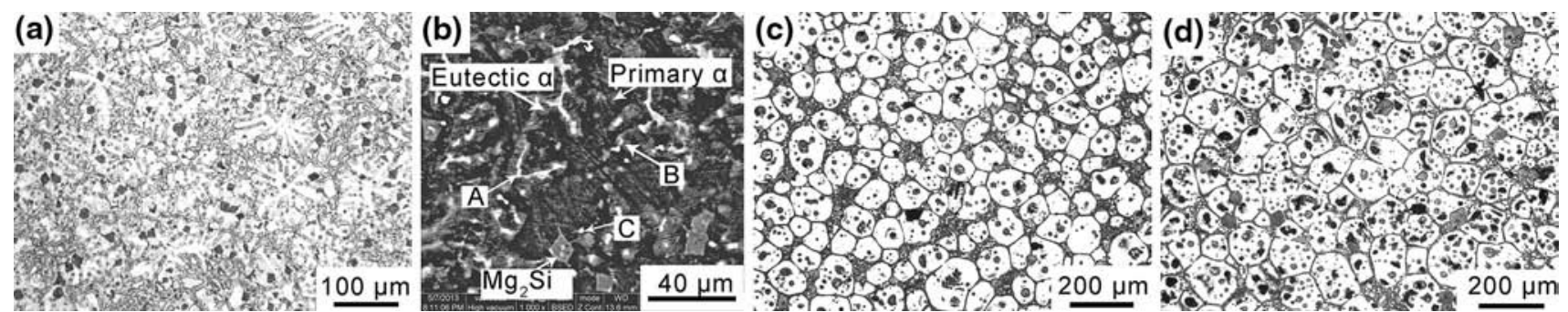

Fig. 2 OM image a and SEM image b showing the microstructure of the as-cast composite, and OM images showing the semisolid microstructures at the edge $\mathbf{c}$ and center $\mathbf{d}$ regions of the ingot (heated for $60 \mathrm{~min}$ at $600{ }^{\circ} \mathrm{C}$ )

deformation during thixoforging. Some typical fracture surfaces were also observed on this SEM.

\section{Results and Discussion}

\subsection{As-cast and Semisolid Microstructures}

For the thixoforging technology, one key procedure is to produce the semisolid feedstocks with small and spheroidal solid particles uniformly distributed in liquid phase [16, 17]. Therefore, whether the $\mathrm{Mg}_{2} \mathrm{Si}_{\mathrm{p}} / \mathrm{AM} 60 \mathrm{~B}$ composite could obtain the desired microstructure after partial remelting should be verified firstly. Figure 2 shows the ascast and semisolid microstructures of the $\mathrm{Mg}_{2} \mathrm{Si}_{\mathrm{p}} / \mathrm{AM} 60 \mathrm{~B}$ composite. As shown in Fig. 2a, the as-cast microstructure is composed of fine and uniform equiaxed dendrites, small polygonal $\mathrm{Mg}_{2} \mathrm{Si}$ particles, and interdendritic eutectics. The eutectic $\beta\left(\mathrm{Mg}_{17} \mathrm{Al}_{12}\right)$ phases are in devoiced eutectic form and discontinuously distributed in the interdendritic regions and the eutectic $\alpha$ phases directly grow on the surfaces of the primary $\alpha$ phases (Fig. $2 b$ ). The polygonal $\mathrm{Mg}_{2} \mathrm{Si}$ particles were distributed in the interdendritic eutectic structures. After the as-cast ingot was heated for $60 \mathrm{~min}$ at $600{ }^{\circ} \mathrm{C}$, the resulting semisolid microstructures at the edge and center region are shown in Fig. $2 \mathrm{c}$ and d, respectively. It can be found that the primary particles are separated each other by the liquid phase, however, those in the edge region are finer $(\sim 90 \mu \mathrm{m})$ and more spheroidal (with shape factor of 1.17), and the liquid fraction is higher (37 vol\%). In addition, the dot-like particles can be found within the primary particles. The EDS analysis result indicates that these particles form from the solidification of the liquid pools entrapped within the primary particles, and the liquid pools result from the eutectic structures in the interdendritic-arm region, as marked by A and B in Fig. 2.

The larger size of the primary particles in the center region of the ingot should result from three reasons. First, the grain size in the center region is always larger than that in the edge region in as-cast ingot. This phenomenon is more obvious for large-sized ingots [24]. The larger the

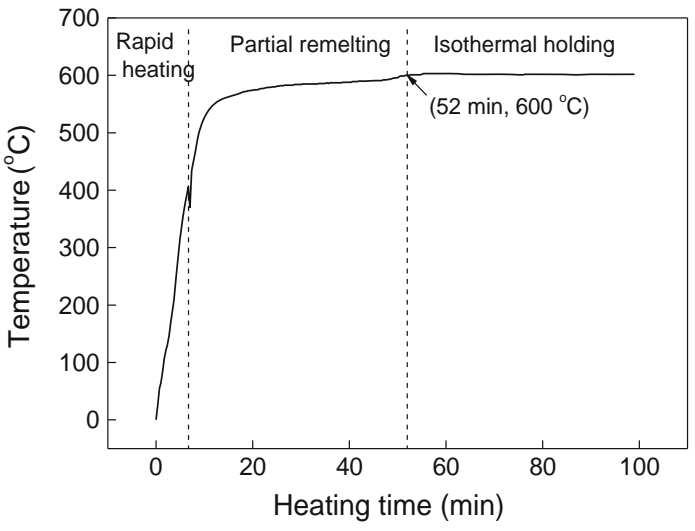

Fig. 3 Temperature variation in the center of the ingot with heating time at $600{ }^{\circ} \mathrm{C}$

grain size of the as-cast microstructure is, the larger the primary particles in the semisolid microstructure is [25, 26]. Second, the employed partial remelting was carried out in an electric resistance furnace, this heating process always generates a large temperature gradient between the center and the edge in an ingot and the gradient increases with increasing ingot dimensions [27]. The temperature in the center region of ingot does not reach the given value until it has been heated for 52 min, as shown in Fig. 3. The longer the reheating time is, the more intensive Ostwald ripening is. Furthermore, the liquid fraction is relatively lower than that in the edge region because the liquid flows toward the edge under the pressure of the gravity of the ingot itself. Therefore, the distance between the neighboring primary particles is relatively short and they are also easy to contact each other. Third, the solidification rate during water quenching in the center region is slower than that in the edge region. Thus, the more secondarily primary $\alpha-\mathrm{Mg}$ phases (to differentiate from the primary particles, the primary $\alpha-\mathrm{Mg}$ phase solidified from the liquid phase is named secondarily primary $\alpha-\mathrm{Mg}$ phase) attach on the primary particle surface. It is difficult to distinguish these two $\alpha-M g$ phases from each other. This not only leads the coarsening of the primary particles, but also decreases the 
secondarily solidified structures that are reflected from the OM image (the liquid fraction seems to decrease). This phenomenon can also been observed in the other thixoforged magnesium alloys [24, 26].

However, a semisolid microstructure with small and spheroidal solid particles uniformly suspended in the liquid matrix can be obtained after the ingot is heated at $600{ }^{\circ} \mathrm{C}$ for $60 \mathrm{~min}$, which implies that the heating technique adopted in this work is appropriate for thixoforging. This can be demonstrated by the following experimental results.

\subsection{Effect of Reheating Duration on Microstructures}

Figure 4 shows the microstructures of the in situ $\mathrm{Mg}_{2} \mathrm{Si}_{\mathrm{p}} /$ AM60B composites thixoforged under different reheating durations at $600{ }^{\circ} \mathrm{C}$. The microstructures are all composed of $\mathrm{Mg}_{2} \mathrm{Si}$ particles, primary particles, and secondarily solidified structures. The secondarily solidified structures in the center regions are always less than that in the edge regions and the difference is increased as the heating time increases. As the reheating duration is prolonged, more secondarily solidified structures are observed in the edge region, while the change in the center region is little. The size and number of the dot-like particles formed from the solidification of liquid pools entrapped within the primary particles firstly increased, and then the number reduced and the size increased, and finally both of them reduced. The primary particles gradually coarsen in both the center and the edge regions with increasing the reheating time. Some large-sized agglomerates of the primary particles can be found when the ingot is heated for long duration (Fig. 4ej). Some of $\mathrm{Mg}_{2} \mathrm{Si}$ particles are engulfed within these agglomerates. As the reheating time increases, the number of the engulfed $\mathrm{Mg}_{2} \mathrm{Si}$ particles is reduced, but some $\mathrm{Mg}_{2} \mathrm{Si}$ particle clusters appear along the primary particle boundaries (Fig. $4 \mathrm{~g}-\mathrm{i}$ ).

Figure 3 indicates that the system reaches the given temperature of $600{ }^{\circ} \mathrm{C}$ till the reheating duration exceeds $52 \mathrm{~min}$. That is to say that the temperature is lower than its given value when the ingot is heated for $50 \mathrm{~min}$. The liquid fraction is still lower than that what the given temperature corresponds to and it will increase with increasing the heating time. It is known that more liquid phase prior to thixoforging must result in more secondarily solidified structure during subsequent thixoforging. However, the secondarily solidified structure amount is almost maintained constant in the center regions of the composites. That is, the resultant microstructure observation in the center regions is conflicted with this standpoint. This can be explained by the following reasons. First, this phenomenon should be related to the inherent characteristics of the employed resistance furnace heating process during partial remelting and the die-filling process during subsequent
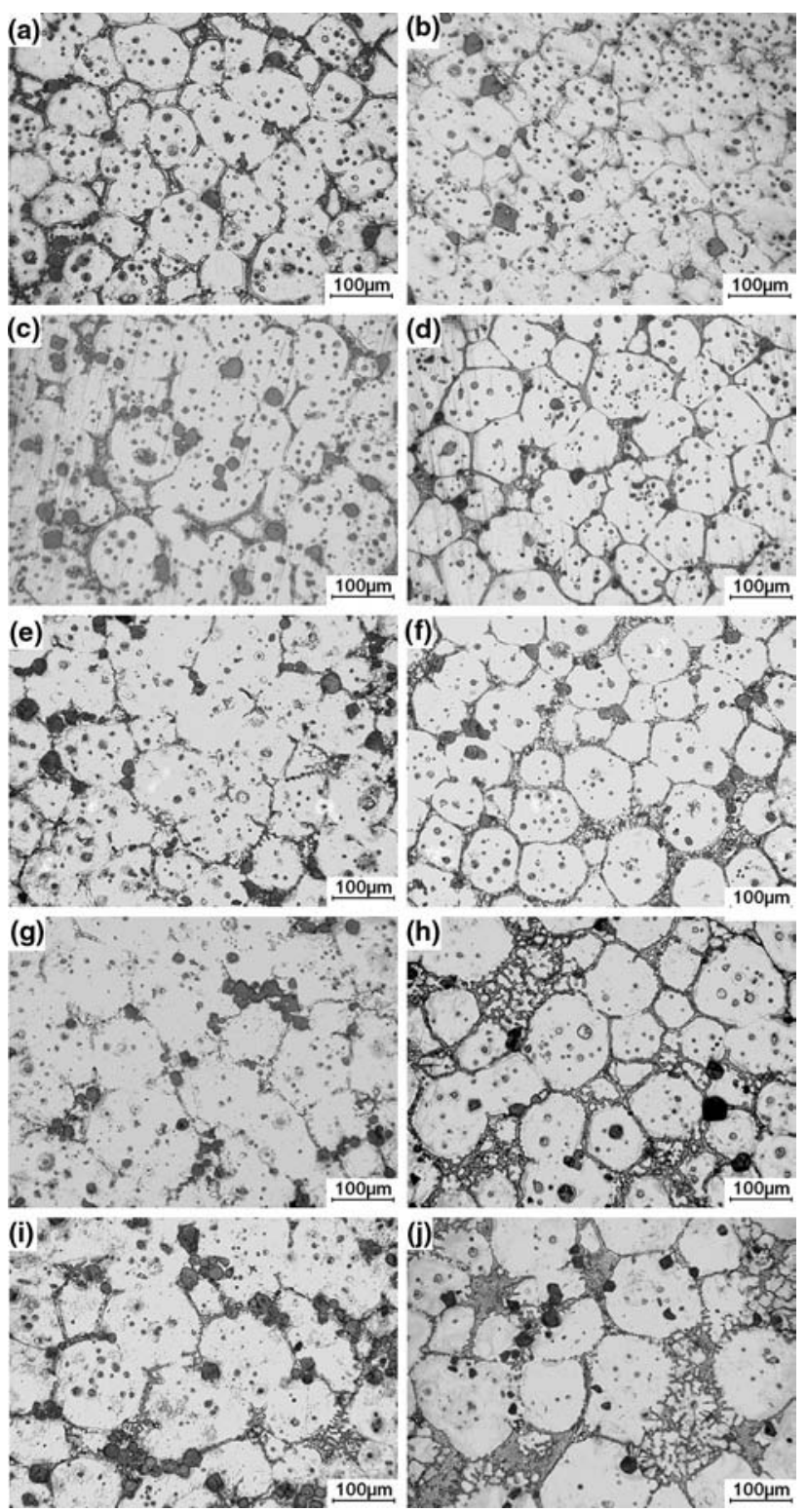

Fig. $4 \mathrm{OM}$ micrographs of the in situ $\mathrm{Mg}_{2} \mathrm{Si}_{\mathrm{p}} / \mathrm{AM} 60 \mathrm{~B}$ composites thixoforged under heating for different durations at $600{ }^{\circ} \mathrm{C}$ : a center region, $50 \mathrm{~min}$; b edge region, $50 \mathrm{~min}$; c center region, $60 \mathrm{~min}$; d edge region, $60 \mathrm{~min}$; e center region, $70 \mathrm{~min} ; \mathbf{f}$ edge region, $70 \mathrm{~min}$; g center region, $90 \mathrm{~min}$; $\mathbf{h}$ edge region, $90 \mathrm{~min}$; $\mathbf{i}$ center region, $120 \mathrm{~min} ; \mathbf{j}$ edge region, $120 \mathrm{~min}$

thixoforging. As mentioned above, the liquid in the edge is always higher than that in the center during partial remelting. And during die-filling, the liquid phase has a flow tendency from the center toward the edge driven by the pressure. This flow results in the difference between the center and edge regions. All of these result in the decrease of liquid amount in the center. Consequently, at the final stage of the deformation, the volume fraction of liquid phase in the center of the products is reduced. Second, the solidification rate in the center is always slower than that in the edge, which leads more secondarily primary $\alpha$-phase to 
Table 1 Compositions of the primary particles in the in situ $\mathrm{Mg}_{2} \mathrm{Si}_{\mathrm{p}}$ / AM60B composites thixoforged under different reheating durations at $600{ }^{\circ} \mathrm{C}$ (in wt $\%$ )

\begin{tabular}{lcc}
\hline Reheating duration $(\min )$ & $\mathrm{Al}$ & $\mathrm{Mg}$ \\
\hline 50 & 4.4 & 95.6 \\
60 & 5.3 & 94.7 \\
70 & 5.8 & 94.2 \\
90 & 4.8 & 95.2 \\
120 & 4.9 & 95.1 \\
\hline
\end{tabular}

attach on the primary particles. Third, this phenomenon is also related to the composition changes of the primary particles. Table 1 gives the primary particle compositions of the composites thixoforged under different reheating durations (only considering the two main elements, $\mathrm{Mg}$ and $\mathrm{Al})$. It indicates that the Al concentration has the similar change trend to that of the other thixoforged magnesium alloys [24], first increases during reheating from 50 to $70 \mathrm{~min}$ and then decreases as the duration prolongs from 70 to $90 \mathrm{~min}$, while the $\mathrm{Al}$ content in the liquid phase has an opposite change trend. This should attribute that the atom diffusion rate lags behind the temperature rise. During the period that the ingot was handled from the resistance furnace to the die cavity, the liquid phase preferentially solidifies on the existing solid particles, which cannot be distinguished from the primary particles [22, 23]. So, it is suggested that when the reheating time is $70 \mathrm{~min}$, a case of the least $\mathrm{Al}$ content in the liquid, the amount of secondarily primary $\alpha-\mathrm{Mg}$ phase attached on the primary particles is the largest. Thus, the amount of secondarily solidified structures seems lower. As the reheating time is further prolonged, although the Al content in the liquid is increased, the more liquid flows toward the edge under the gravity of the ingot itself, resulting in the decrease of the secondarily solidified structure in the center. So, the amount of the secondarily solidified structure in the center region has little change (Fig. 4).

Moreover, Al element is a necessary constituent for forming eutectic $\beta$ phase. Figure 5 reveals that the change trend of the eutectic $\beta$ phase amount is just contrary to that

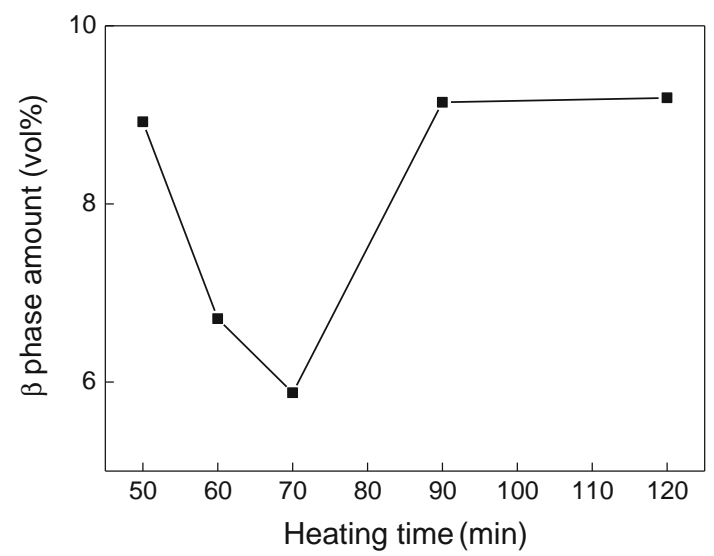

Fig. 6 Variation of the $\beta$ phase amount with reheating duration

of the $\mathrm{Al}$ content in the primary particles with the reheating duration. The corresponding quantitative examination is shown in Fig. 6. These results further demonstrate the standpoint mentioned above.

To more obviously clarify the above standpoint, micrographs with high magnification are shown in Fig. 7. It can be seen that the thickness of the secondarily primary $\alpha$ $\mathrm{Mg}$ phase attached on the primary particles first increases and then decreases as the reheating time increases. The results are just consistent to the above discussion.

The evolution of the dot-like structures solidified from the liquid pools entrapped within the primary particles is more obviously observed in Fig. 7. When the ingot is heated for $50 \mathrm{~min}$, the temperature does not reach the given value. So, the number and size of the liquid pools within the primary particles are very small. As the reheating time increases to $60 \mathrm{~min}$, both the number and size are increased due to the temperature rise (Fig. 3). When the reheating duration extends to $70 \mathrm{~min}$, the liquid pools coarsen driven by minimizing the solid/liquid interface energy [31], resulting in the number decrease and the size increase. Because of the melting rate lags behind the temperature rise, the coarsening of the liquid pools partially is attributed to the partial melting of the solid $\alpha-\mathrm{Mg}$ around them during the period from 60 to $70 \mathrm{~min}$. When the reheating time is
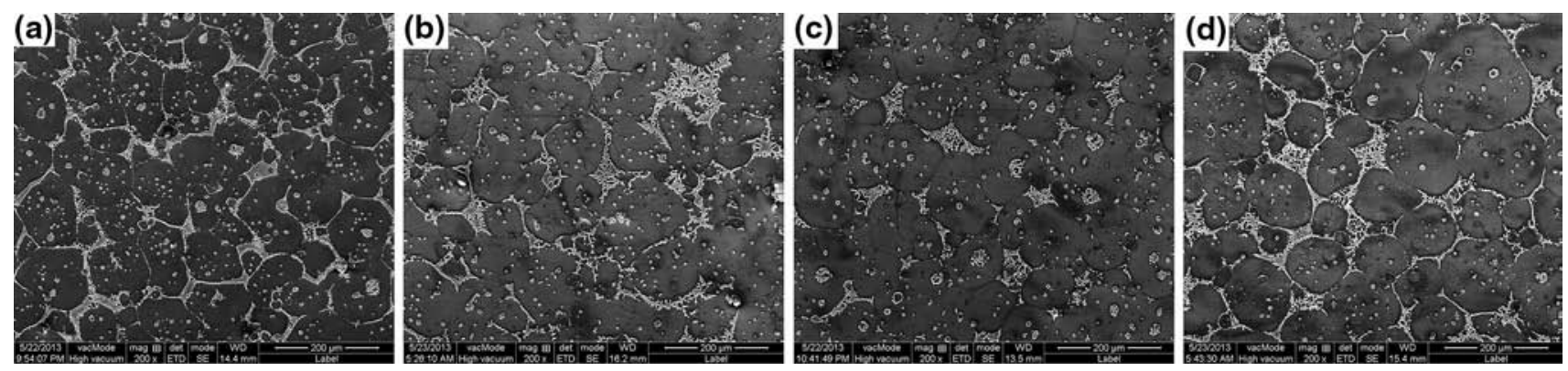

Fig. 5 SEM images in the center regions of the composites thixoforged under reheating at $600{ }^{\circ} \mathrm{C}$ for $50 \mathrm{~min} \mathbf{a}, 60 \mathrm{~min} \mathbf{b}, 70 \mathrm{~min} \mathbf{c}, 90 \mathrm{~min} \mathbf{d}$ 

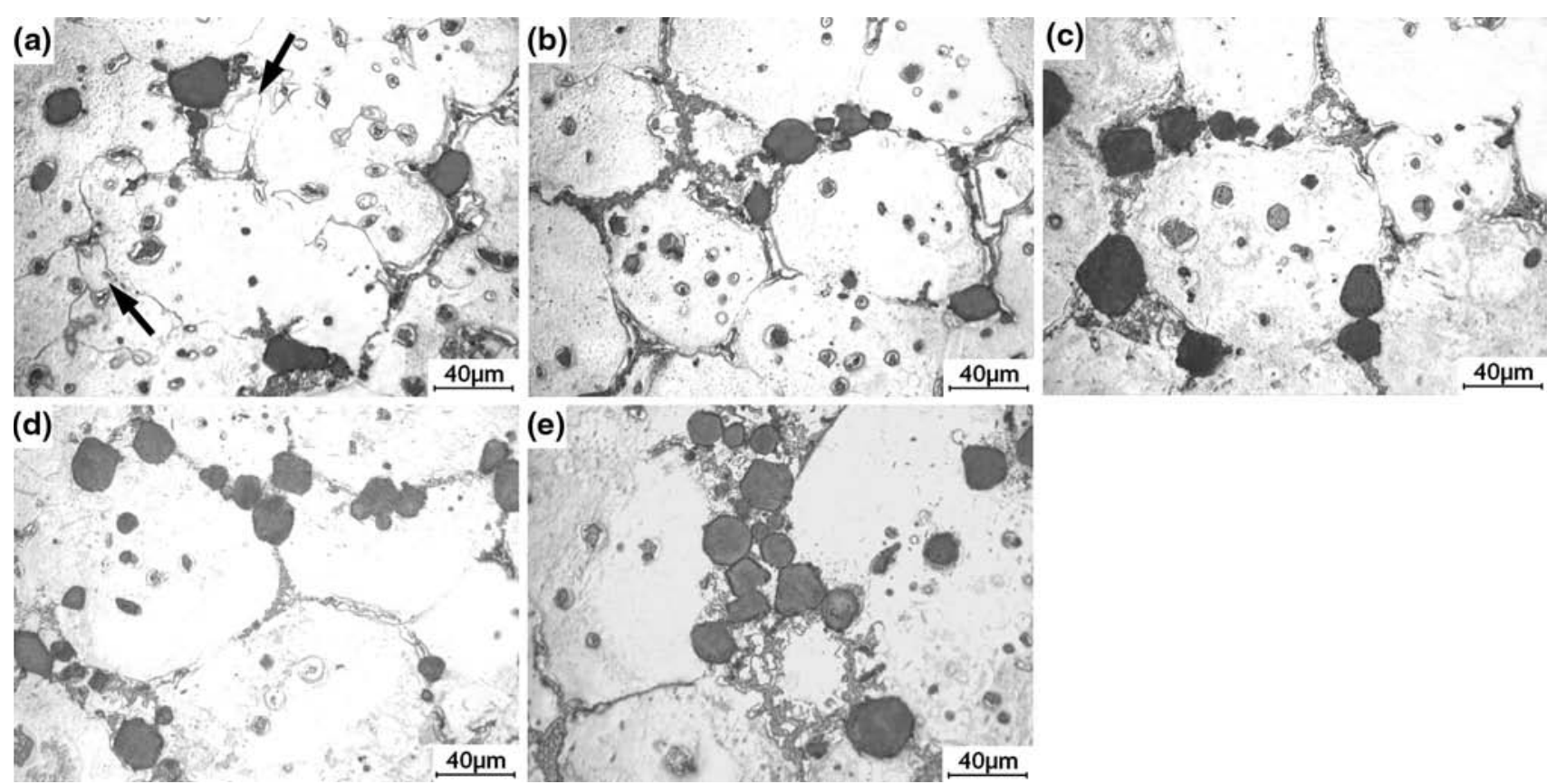

Fig. $7 \mathrm{OM}$ images of the center regions of the composites thixoforged under reheating for $50 \mathrm{~min} \mathbf{a}, 60 \mathrm{~min} \mathbf{b}, 70 \mathrm{~min} \mathbf{c}, 90 \mathrm{~min} \mathbf{d}, 120 \mathrm{~min} \mathbf{e}$

prolonged to $90 \mathrm{~min}$, the amount of the entrapped liquid pools decreases, but in some triple points among the primary particles, some liquid phases are entrapped by the agglomerated primary particles. It is suggested that these liquid pools move toward the inter-particles liquid through diffusion. And as the reheating time exceeds $120 \mathrm{~min}$, the inner liquid connects with the inter-particles liquid phase to form effectively liquid, resulting in decrease in its amount. The detailed investigation is in Ref. [28].

The $\mathrm{Mg}_{2} \mathrm{Si}$ particles in the as-cast microstructure are in irregular particles with sharp edges and corners (Fig. 2b). After being heated for $50 \mathrm{~min}$, their sharp edges and corners became blunt due to the partial melting [29]. As the heating time increases, the $\mathrm{Mg}_{2} \mathrm{Si}$ particles become more spheroidal and agglomerated (comparing Fig. 7b-d). The spheroidization of the $\mathrm{Mg}_{2} \mathrm{Si}$ particles is also attributed to the partial melting from temperature rising during the period from 50 to $60 \mathrm{~min}$, and then driven by minimizing the solid/liquid interface energy during the period from 60 to $120 \mathrm{~min}$ [29]. The agglomeration of the $\mathrm{Mg}_{2} \mathrm{Si}$ particles over 120 min should also result from this reason (Fig. 7e).

Figure 7a presents that a kind of small grains forms in some local regions (marked by arrows). It is suggested that these small grains form due to the plastic deformation and subsequent recrystallization. Although the $\alpha$-Mg particles have been deformed during thixoforging, the demolding time and cooling time are relatively too short to realize the complete recrystallization. To examine the deformation degree occurred during thixoforging, the specimens are subjected to a solution treatment. It is expected that the deformation degree can be qualitatively examined from the resultant recrystallized fine grains. Figure 8 shows the solution-treated microstructures. There are four deformation regimes during thixoforging: liquid flow (LF), flow of liquid incorporating solid particles (FLSs), sliding between solid particles (SSs), and plastic deformation of solid particles (PDS). The former two regimes operate under the condition that the solid particles are surrounded by liquid phase and the latter two carry out when the solid particles are in contact each other. The former two regimes always operate prior to the latter two because the responsive time of the former two regimes is shorter than the latter two [30].

When the reheating time is the shortest one of $50 \mathrm{~min}$, the liquid phase amount prior to thixoforging is the least. In this case, there is no enough liquid to realize the deformation through LF, FLSs, and SSs in some local zones. Consequently, the $\alpha-\mathrm{Mg}$ particles will contribute to deformation. Thus, many small grains generate from the recrystallization during solution treatment (Fig. 8a).

As the reheating time increases to $60 \mathrm{~min}$, the more liquid phase generates in the semisolid ingot. Under this condition, the deformation of the $\alpha-\mathrm{Mg}$ particles will decrease due to the lubrication of liquid phase. As shown in Fig. $8 \mathrm{~b}$, the recrystallization only operates in some particular primary particles. So, the deformation mechanisms during thixoforging should operate in the SSs and PDS regimes. 

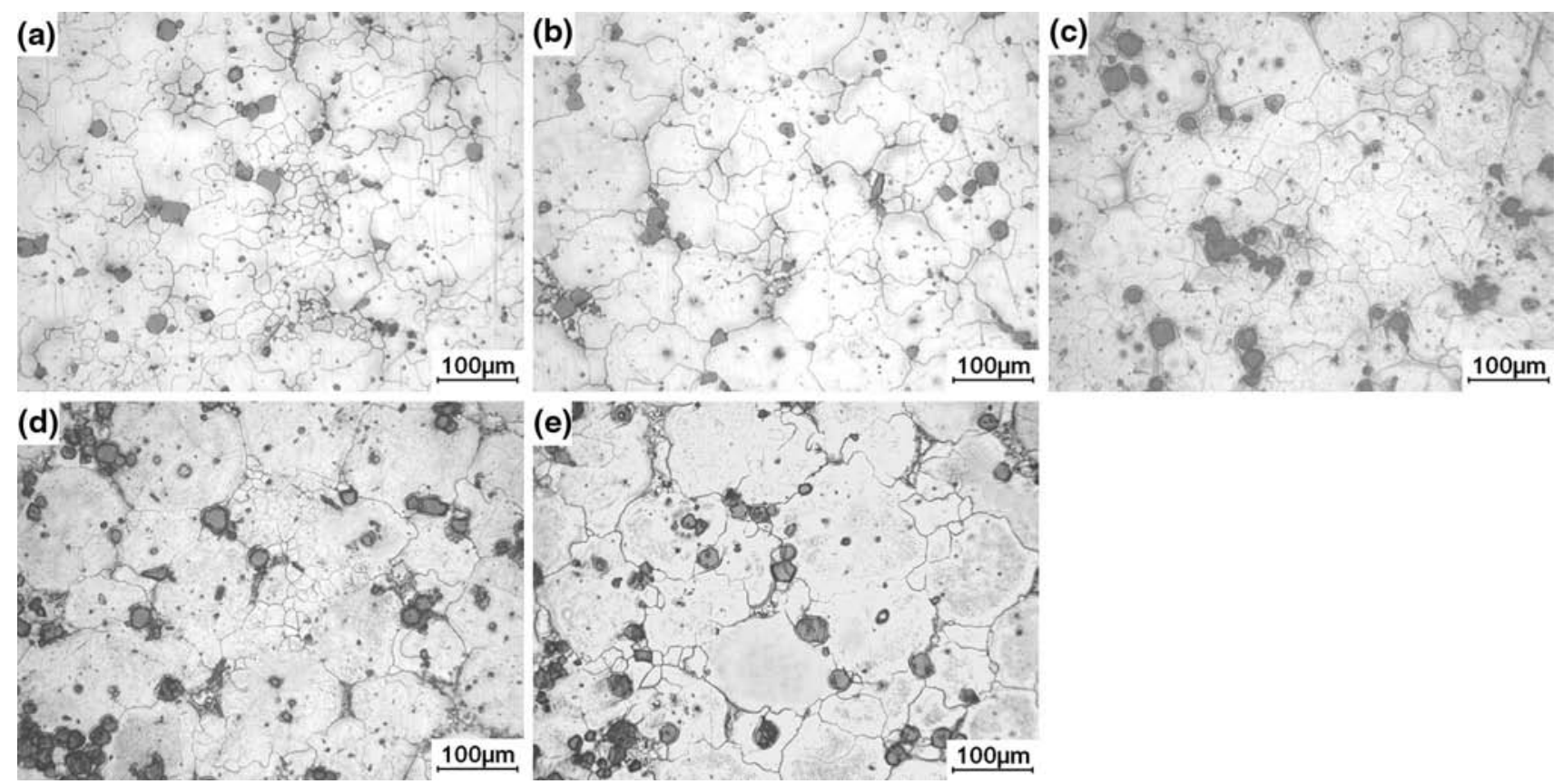

Fig. $8 \mathrm{OM}$ micrographs of the composites thixoforged under reheating for different durations and then solution treated for $1 \mathrm{~h}$ at $430{ }^{\circ} \mathrm{C}$ : a $50 \mathrm{~min}$; b $60 \mathrm{~min}$; c $70 \mathrm{~min}$; d $90 \mathrm{~min}$; e $120 \mathrm{~min}$

When the reheating time exceeds 70 min, liquid phase obviously increases and the deformation carries out in the LF regime. So, more liquid phase is squeezed out and large amount of secondarily solidified structures generate in the edge region (Fig. 4). It is just due to this deformation regime, the liquid phase in the center region decreases and the primary particles then contact each other. The deformation mechanisms thereby transform into the SSs and PDS regimes. During sliding, the contact sites between the primary particles preferentially participate in plastic deformation. Thus, many small grains generate in the marginal regions of the primary particles as shown in Fig. 8c. Therefore, the deformation operates in LF regime at the initial stage of the deformation, then transforms into SSs and slight PDS regimes at the final stage. Of cause, the FLSs regime operates in the transition stage from LF transform into SSs.

Figure 4g shows that the large-sized agglomerates can be observed when the reheating duration is prolonged to $90 \mathrm{~min}$. In fact, these agglomerates always exist in the original semisolid ingots prepared by partial remelting and their number increases as the heating time increases. At the final stage of thixoforging, the solid particles slide each other by lubrication of the eutectic liquid. However, these large-sized agglomerates present a bad deformation harmony. So, shear bands like the deformation of solid alloy can generate within the agglomerates. As a result, some lines of small grains through recrystallization are observed (Fig. 8d). Thus, in this situation, the deformation during thixoforging should operate in the sequence of LF, FLSs, SSs, and PDS.
When the reheating time exceeds $120 \mathrm{~min}$, more entrapped liquid pools move toward the inter-particle liquid phase, and thus the lubrication action of liquid phase is improved. So, the plastic deformation degree is weakened. But the deformation should operate in the same regimes to those of the ingot heated for $90 \mathrm{~min}$.

Based on the above discussion, it can be concluded that the SSs and PDS regimes are dominant deformation mechanisms for the composites thixoforged under the short reheating times. However, for those thixoforged under long-heating durations, the LF and FLSs regimes first operate, and then the SSs and PDS regimes in turn carry out. Actually, the deformation mechanisms during thixoforging are very complex. The effects of the other processing parameters on the deformation mechanisms will be discussed in the further work.

In summary, the microstructure evolution with reheating time is ascribed to the variations of liquid phase amount, distribution and composition, the liquid pools within the primary particles, and the $\mathrm{Mg}_{2} \mathrm{Si}$ particle morphology and distribution of the semisolid ingot. These changes affect the subsequent solidification behavior and plastic deformation mechanisms during thixoforging.

\subsection{Effect of Reheating Duration on Tensile Properties}

Figure 9 gives the curves of the tensile properties versus the reheating duration. At the reheating time of $50 \mathrm{~min}$, the UTS is the lowest one. As the reheating duration increases to $60 \mathrm{~min}$, the UTS is significantly improved. However, 


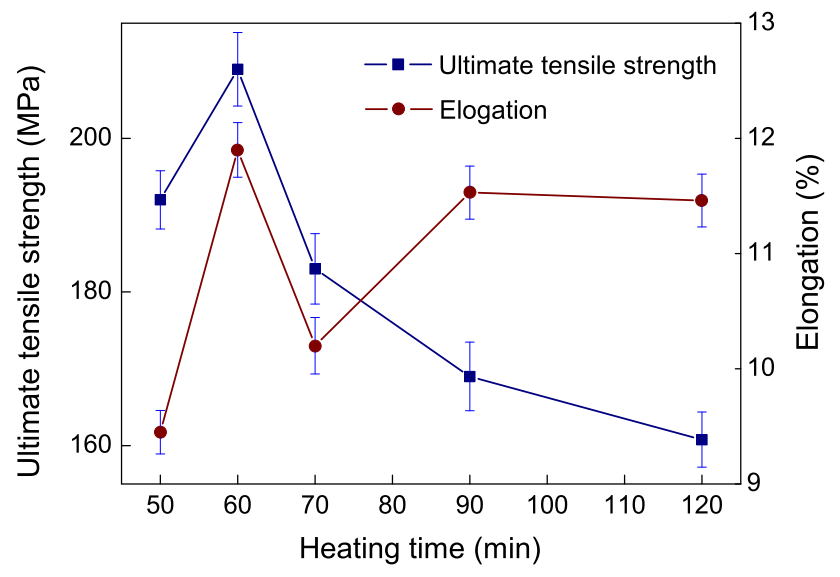

Fig. 9 Variations of UTS and elongation with reheating duration

with further increasing the reheating time, the UTS gradually decreases. The elongation increases first and then decreases when the reheating time exceeds 70 min. However, it increases again as the reheating time is prolonged to 90 min. It can be found that the composite thixoforged under reheating at $600{ }^{\circ} \mathrm{C}$ for $60 \mathrm{~min}$ has the best comprehensive mechanical properties, UTS of $209 \mathrm{MPa}$, and elongation of $11.9 \%$.
Figure 10a indicates that the fracture surface of the composite thixoforged under reheating for $50 \mathrm{~min}$ is characterized by large-sized pits and large irregular particles. The side view of the fracture surface (Fig. 11a) shows that cracks frequently propagate between the $\alpha$-Mg particles during tensile testing (marked by A) and occasionally across the $\alpha-\mathrm{Mg}$ particles and the small black particles within the $\alpha-\mathrm{Mg}$ particles (marked by B). These large pits and irregular particles should correspond to the debonding of the neighboring primary particles. Under this condition, the flowability, mold filling ability, and feeding ability are the worst. The microcracks may form between the primary particles during thixoforging. There is no enough liquid to feed the formed microcracks. As a result, the bonding strength of the primary particles is the worst. Therefore, cracks preferentially developed along these structures during tensile testing. This phenomenon is quite common and can be found in other thixoforged alloys [23]. The black particles within the primary particles are also the weak points of the composites. These particles resulted from solidification of the liquid pools within the original primary particles. It can be expected that there is no extra liquid to feed the solidification shrinkage of the liquid pools during thixoforging, and thus, porosities easily
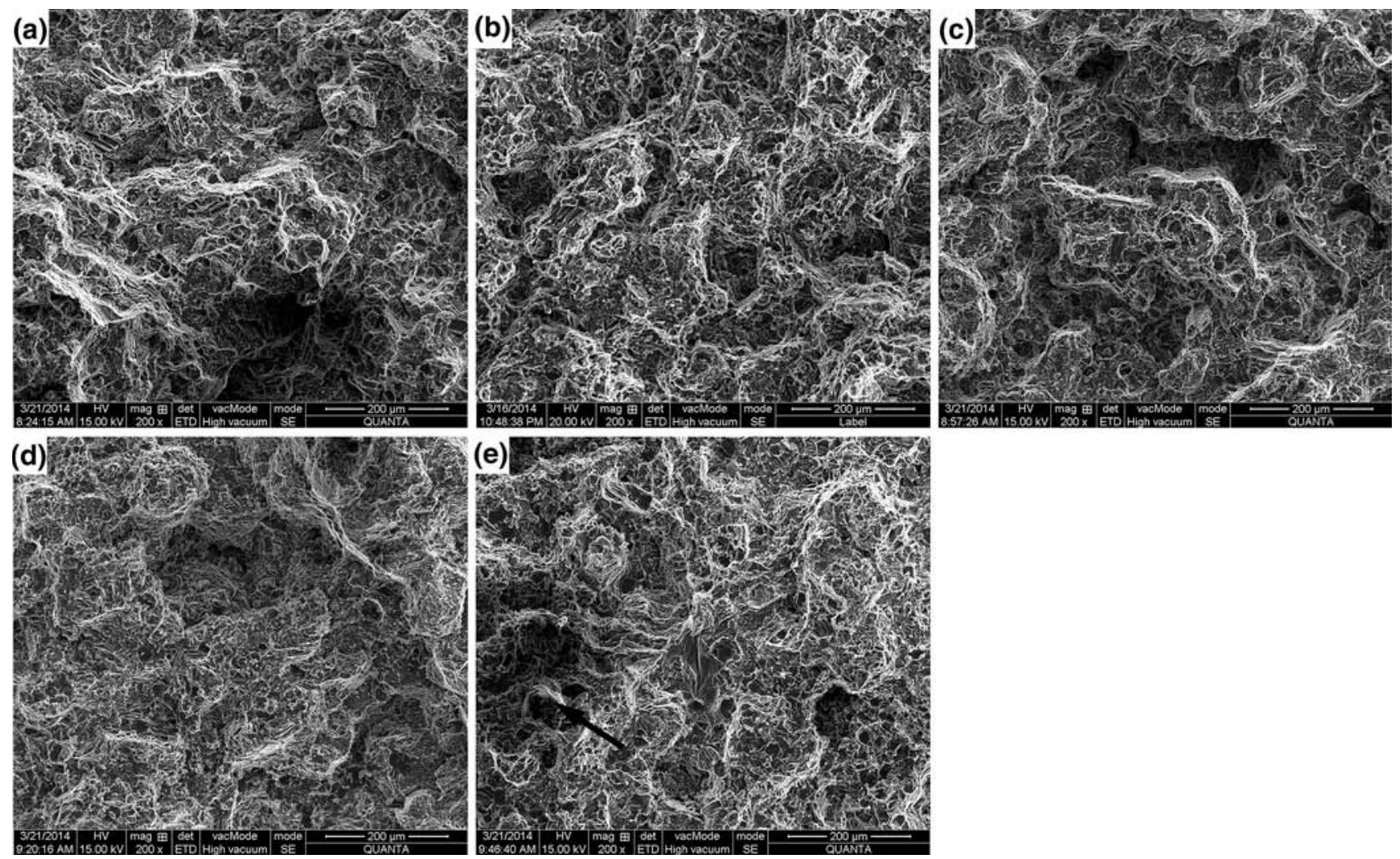

Fig. 10 Fractographs of composites thixoforged under different reheating durations at $600{ }^{\circ} \mathrm{C}$ : a $50 \mathrm{~min}$; b $60 \mathrm{~min}$; c $70 \mathrm{~min}$; d $90 \mathrm{~min}$; e $120 \mathrm{~min}$ 

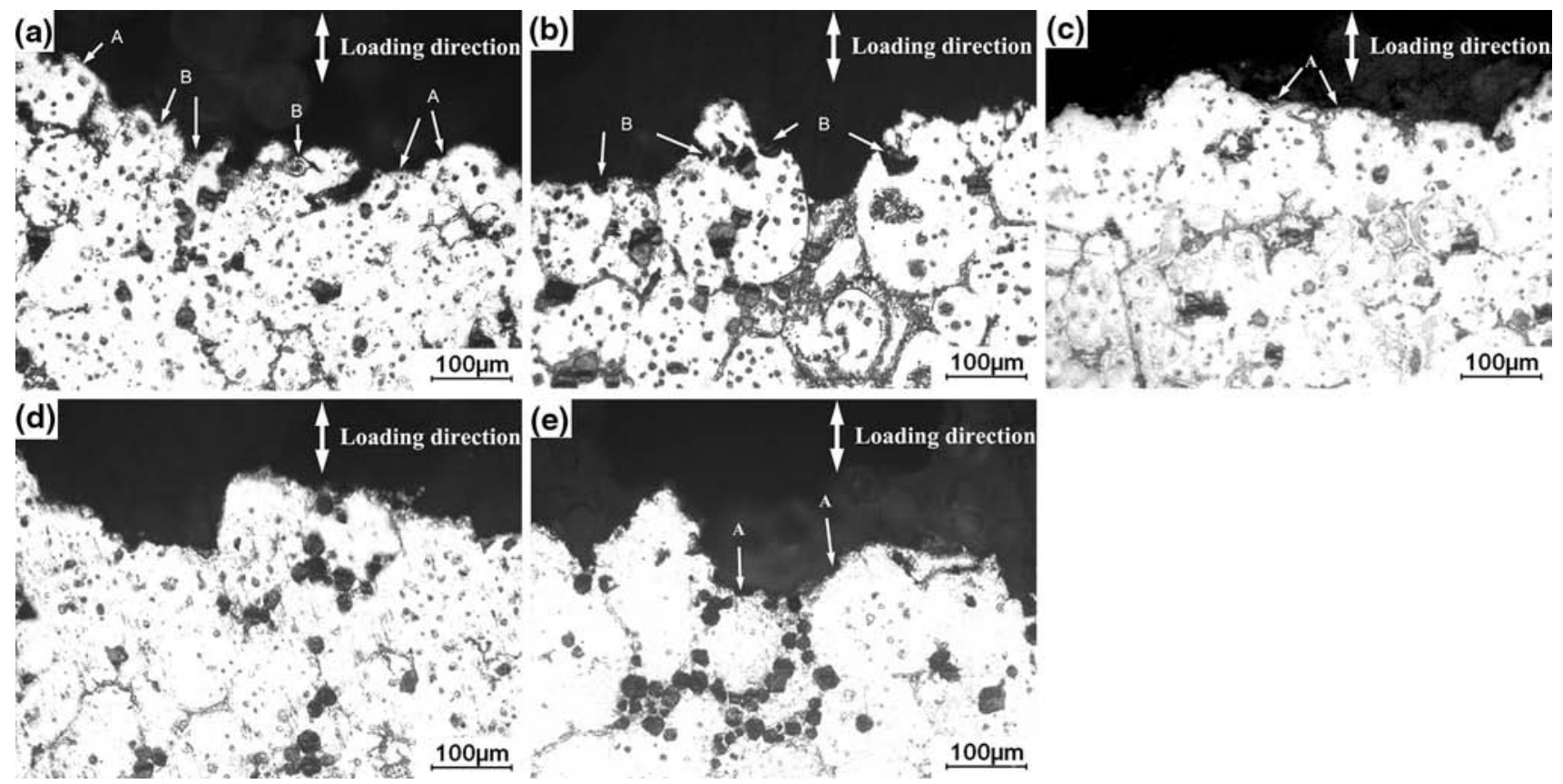

Fig. 11 Side views of composite fracture surfaces thixoforged under different reheating durations at $600{ }^{\circ} \mathrm{C}$ : a $50 \mathrm{~min}$; b $60 \mathrm{~min}$; c $70 \mathrm{~min}$; d $90 \mathrm{~min}$; e $120 \mathrm{~min}$

generate in the black particles. Therefore, cracks also preferentially pass these sites when they develop across the primary particles. So, it can be suggested that the fracture of this composite belongs to a mixture of transgranular and intergranular modes. The un-compact microstructure is responsible for the relatively inferior properties of the composite.

As the reheating time increases to $60 \mathrm{~min}$, the liquid phase amount increases, and thus the flowability, mold filling ability, and particularly the feeding ability to solidification shrinkage during thixoforging are improved. So, the microstructure compactness is enhanced. Consequently, the bonding strength between the primary particles is improved. Moreover, as discussed in the above section, the solubility of $\mathrm{Al}$ in the $\alpha-\mathrm{Mg}$ particles increases and the amount of eutectic $\beta$ phase decreases. The solution strengthening role is enhanced and the harmfulness of eutectic $\beta$ phase is decreased. Both these two changes improve the tensile properties. As a result, the large-sized irregular particles resulting from particle debonding are seldom found on the fracture surface (Fig. 10b), and the surface is characterized by uniform small dimples. In this case, cracks develop across the primary particles and the black structures (marked by B) within the primary particles (Fig. 11b). The fracture regime changes into transgranular modes. It is just this reason that the composite thixoforged under reheating for $60 \mathrm{~min}$ has the superior tensile properties.

When the reheating time increases to $70 \mathrm{~min}$, the fracture surface is characterized by relatively large-sized irregular particles, cracks, and holes (Fig. 10c). The side view of the fracture surface shows that the fracture basically belongs to intergranular regime (Fig. 11c). Both of the results imply that the primary particles are easily debonded. The holes result from the debonding of the $\mathrm{Mg}_{2} \mathrm{Si} /$ matrix. The cracks imply that local stress concentration exists in these zones. As mentioned above, the deformation during thixoforging occurs at marginal regions of the $\alpha-\mathrm{Mg}$ particles, and seldom expanded to the inner of the $\alpha-M g$ particles. That results in the high density of dislocations in these regions. Cracks would initiate at these regions during tensile testing. In this case, the interface of $\alpha-\mathrm{Mg} / \alpha-\mathrm{Mg}$ and $\mathrm{Mg}_{2} \mathrm{Si} /$ matrix is easily debonded during tensile testing. In addition to the local stress concentration, the large-sized agglomerates play a role in decreasing the tensile properties. Thus, the local stress concentration and large-sized agglomerates are responsible for the decrease in the tensile properties.

As the reheating time prolonged to $90 \mathrm{~min}$, the fracture surface is characterized by large-sized cleavage facets (Fig. 10d), and the side view of the fracture surface indicates that the fracture belongs to a transgranular mode (Fig. 11d). Many agglomerates composed of several primary particles generate in the original semisolid ingots. Large amounts of liquid phase are entrapped within these agglomerates and this is the weak point of the composites during tensile test owing to there is no extra liquid to feed solidification shrinkage of them during thixoforging. Cracks preferentially initiate at these sites. Thus, the 

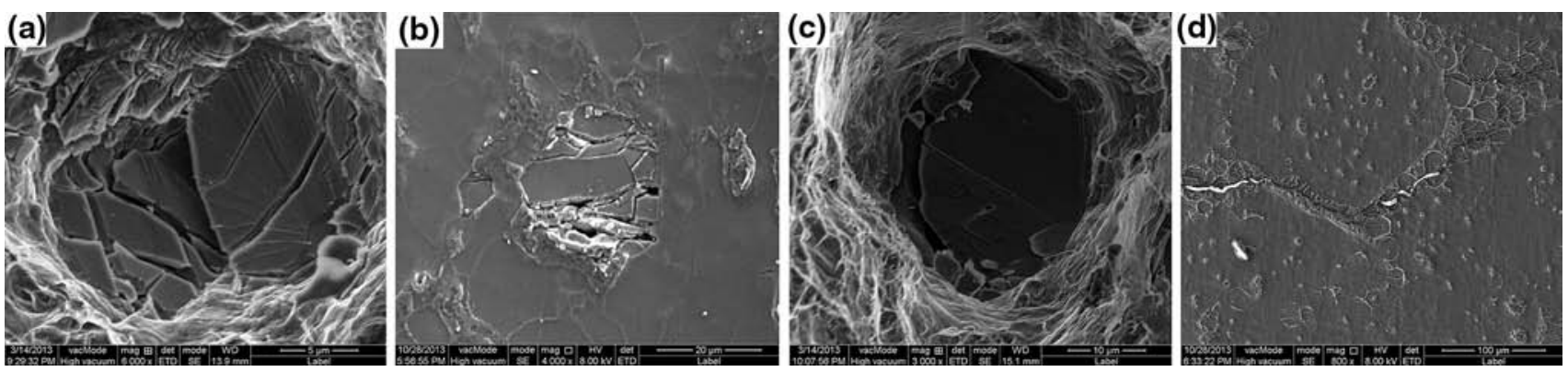

Fig. 12 Typical fractographs and fracture surface side views of the composites: a fragmented $\mathrm{Mg}_{2} \mathrm{Si}$ particles; $\mathbf{b}$ side view of fragmented $\mathrm{Mg}_{2} \mathrm{Si}$ particle of the composite thixoforged under reheating for $60 \mathrm{~min} ; \mathbf{c} \mathrm{Mg}_{2} \mathrm{Si} /$ matrix interface debonding of the composite thixoforged under reheating for $70 \mathrm{~min}$; $\mathbf{d ~} \mathrm{Mg}_{2} \mathrm{Si}$ clusters in the composite thixoforged under reheating for $120 \mathrm{~min}$

decreasing of the UTS is mainly ascribed to the liquid within the agglomerates.

When the reheating time exceeds 120 min, the liquid within the agglomerates moves toward the inter-particle liquid. Although these liquid amounts reduced in total, but it still exists within some agglomerates, and thus cracks preferentially pass these sites. Moreover, the $\mathrm{Mg}_{2} \mathrm{Si}$ particle clusters were located along the primary particles boundaries, resulting in decreasing the bonding strength of the primary particles. Thus, as shown in Fig. 10e, large irregular particles are observed, which correspond to the region in which cracks develop along the secondarily solidified structures between the primary particles (marked by $\mathrm{A}$ in Fig. 11e). In addition, the oxide inclusions (marked by arrow) also could be found in Fig. 10e, it could be reasonably concluded that the longer the reheating time is, the higher probability to form oxide inclusions at $600{ }^{\circ} \mathrm{C}$. Therefore, the decrease of the tensile properties is owing to the entrapped liquid, the $\mathrm{Mg}_{2} \mathrm{Si}$ particle clusters, and the oxide inclusions.

The $\mathrm{Mg}_{2} \mathrm{Si}$ particles in the composites should play a strengthening role for the matrix. From the observations under larger magnification of the fracture surfaces are shown in Fig. 12. It can be seen that three phenomena are related to the $\mathrm{Mg}_{2} \mathrm{Si}$ particles, the fragmentation, the debonding of $\mathrm{Mg}_{2} \mathrm{Si} /$ matrix interface, and the $\mathrm{Mg}_{2} \mathrm{Si}$ clusters. The first phenomenon is generated when both the $\mathrm{Mg}_{2} \mathrm{Si} /$ matrix interface bonding strength and matrix strength are strong. In this case, stress concentration preferentially generates at the sharp edges and corners of the interfaces during tensile testing. The stress concentration increases to a degree and then results in the fragmentation of the $\mathrm{Mg}_{2} \mathrm{Si}$ particles. This phenomenon is often observed under reheating duration from 50 to $60 \mathrm{~min}$ (Fig. 12a). Figure $12 \mathrm{~b}$ presents a fragmented $\mathrm{Mg}_{2} \mathrm{Si}$ particle near the fracture surface in side view of fracture surface. The fragmentation relaxes stress concentration in local zones and hinders the cracks initiation and propagation in the matrix. Thus, the $\mathrm{Mg}_{2} \mathrm{Si}$ particles effectively reinforce the matrix through the load transfer mechanism. The second phenomenon occurs when the $\mathrm{Mg}_{2} \mathrm{Si} /$ matrix interfaces are easy to debond. Focused on the composite thixoforged under reheating for $70 \mathrm{~min}$, the generated stress concentrates upon the $\mathrm{Mg}_{2} \mathrm{Si} /$ matrix interfaces and leads the $\mathrm{Mg}_{2} \mathrm{Si} /$ matrix interfaces to debond under the external load (Fig. 12c). The matrix around the $\mathrm{Mg}_{2} \mathrm{Si}$ particle then plastically deforms and a hole with plastic tearing feature is left on the fracture surface as shown in Fig. 12c. The third phenomenon is often observed for the composites under long reheating durations ( $>90 \mathrm{~min}$ ). The $\mathrm{Mg}_{2} \mathrm{Si}$ clusters result in bad microstructure compactness and high local stress concentration in these regions. Figure $12 \mathrm{~d}$ shows that cracks propagate across the $\mathrm{Mg}_{2} \mathrm{Si}$ cluster in the composite thixoforged under reheating for $120 \mathrm{~min}$. Both of the latter two phenomena have harmfulness to tensile properties and should be avoided through adjusting the reheating technique. In summarily, the $\mathrm{Mg}_{2} \mathrm{Si}$ particles efficiently strength the matrix through load transfers mechanism, and the $\mathrm{Mg}_{2} \mathrm{Si}$ particle agglomerates should be avoided as far as possible.

Therefore, it can be summarized that the reheating time has large effects on tensile properties of the thixoforged composites. The changes of tensile properties are mainly related to some defects, local stress concentration determined by plastic deformation, shrinkage porosities, $\mathrm{Mg}_{2} \mathrm{Si}$ clusters, and oxide inclusions. The composites formed under reheating for $60 \mathrm{~min}$ at $600{ }^{\circ} \mathrm{C}$ have the best comprehensive tensile properties, UTS of $209 \mathrm{MPa}$, and elongation of $11.9 \%$.

\section{Conclusions}

(1) The reheating time affects the amount, composition, and distribution of the liquid phase, the evolution of the liquid pools within the primary particles, the morphology and distribution of the $\mathrm{Mg}_{2} \mathrm{Si}$ particles and primary particles in the semisolid ingots, and thus 
the subsequent solidification behavior and deformation mechanism and finally the tensile properties.

(2) The primary particles in the microstructure gradually coarsen and the secondarily solidified structures increase in the edge of the products, but have little change in the center as the heating time rises. Such microstructure evolution results mainly from the changes of solidification behavior and deformation mechanism which is determined by liquid amount, composition, and distribution prior thixoforging.

(3) The tensile properties are mainly determined by the shrinkage porosities, stress concentration, $\mathrm{Mg}_{2} \mathrm{Si}$ clusters, and oxide inclusions.

(4) The bonding strength of the $\mathrm{Mg}_{2} \mathrm{Si}_{\mathrm{p}} /$ matrix interface is relatively strong. The $\mathrm{Mg}_{2} \mathrm{Si}$ particles play a strengthening role for the matrix through load transfer behavior and are able to efficiently retard crack propagation.

(5) The appropriate reheating duration is $60 \mathrm{~min}$ at $600{ }^{\circ} \mathrm{C}$ when the mold preheating temperature is $300{ }^{\circ} \mathrm{C}$. The UTS and elongation of the thixoforged composite are up to $209 \mathrm{MPa}$ and $10.2 \%$, respectively.

\section{References}

[1] M. Easton, A. Beer, M. Barnett, C. Davies, G. Dunlop, Y. Durandet, JOM 60, 57 (2008)

[2] D. Eliezer, E. Aghion, F.H. Froes, Adv. Perform. Mater. 5, 201 (1998)

[3] L.H. Wen, Z.S. Ji, X.L. Li, Mater. Charact. 59, 1655 (2008)

[4] D.H. Stjohn, M. Qian, M.A. Easton, P. Cao, Z. Hildebrand, Metall. Mater. Trans. A 36, 1668 (2005)

[5] P. Niskanen, W.R. Mohu, Adv. Mater. Process. 3, 39 (1988)

[6] T.J. Chen, M.F. Fu, Y.D. Li, Int. J. Cast Met. Res. 24, 299 (2011)
[7] H.Y. Wang, Q.C. Jiang, B.X. Ma, Y. Wang, J.G. Wang, J.B. Li, Mater. Sci. Eng. A 368, 159 (2004)

[8] X.Q. Wu, H. Yan, Y. Hu, Hot Work. Technol. 39, 71 (2010)

[9] Y.Z. Lu, Q.D. Wang, X.Q. Zeng, W.J. Ding, Y.P. Zhu, Mater. Sci. Technol. 17, 207 (2001)

[10] L. Shen, T.J. Chen, Y. Ma, Spec. Cast. Nonferrous Alloys 31, $653(2011)$

[11] C.P. Wang, H.S. Mei, R.Q. Li, D.F. Li, L. Wang, J. Liu, Z.H. Hua, L.J. Zhao, F.F. Pen, H. Li, Acta Metall. Sin. (Engl. Lett.) 26, 149 (2013)

[12] M. Suery, M.C. Flemings, Metall. Trans. A 13, 1890 (1982)

[13] V. Laxmann, M.C. Flemings, Metall. Trans. A 11, 1927 (1980)

[14] Q. Chen, S.J. Luo, Z.D. Zhao, J. Alloys Compd. 477, 726 (2009)

[15] Z. Fan, J. Int. Mater. Rev. 47, 49 (2002)

[16] T.J. Chen, X.D. Jiang, Y. Ma, Y.D. Li, Y. Hao, J. Alloys Compd. 497, 147 (2010)

[17] T.J. Chen, R.Q. Wang, Y. Ma, H.J. Huang, Y. Hao, Int. J. Mater. Res. 102, 1459 (2011)

[18] L. Shen, Ph.D. dissertation, Lanzhou University of Technology, 2011

[19] T.J. Chen, G.X. Lu, Y. Ma, Y.D. Li, Y. Hao, J. Alloys Compd. 486, 124 (2009)

[20] T.J. Chen, R.Q. Wang, Y. Ma, Y. Hao, J. Mater. Res. 14, 532 (2011)

[21] T.J. Chen, R.Q. Wang, Y. Ma, Y.D. Li, Y. Hao, J. Trans, Nonferrous Met. Soc. China 20, 1615 (2010)

[22] H.V. Atkinson, Mater. Sci. Technol. 26, 1401 (2010)

[23] T.J. Chen, L.K. Huang, X.F. Huang, Y. Ma, Y. Hao, J. Alloys Compd. 556, 167 (2013)

[24] T.J. Chen, L.K. Huang, X.F. Huang, Y. Ma, Y. Hao, Mater. Sci. Technol. 30, 96 (2014)

[25] T.J. Chen, X.D. Jiang, Y. Ma, Y.D. Li, Y. Hao, J. Alloys Compd. 505, 476 (2010)

[26] T.J. Chen, W.B. Lv, Y. Ma, H.J. Huang, Y. Hao, Mater. Res. 102, 1459 (2011)

[27] T.J. Chen, Y. Hao, Y.D. Li, Met. Mater. Int. 11, 513 (2005)

[28] S.Q. Zhang, T.J. Chen, Y. Ma, Y.D. Li, Y. Hao, Appl. Mech. Mater. 446-447, 55 (2014)

[29] P.C. Chen, L.M. Zhu, Z. Li, Fundamental of metal forming, (China Machine Press, Beijing, 2003), p.77. (in Chinese)

[30] P.C. Chen, C.Y.A. Tsao, Acta Mater. 45, 1955 (1997)

[31] E. Tzimas, A. Zavaliangos, Mater. Sci. Eng. A 289, 228 (2000) 